\title{
The Informal Urban Communities Initiative: Community-Driven Design in the Slums of Lima, Peru
}

\author{
Ben Spencer \\ Asst. Professor, Department of Landscape Architecture \\ Adjunct Asst. Professor, Department of Global Health \\ University of Washington \\ Seattle, WA 98105 \\ bspen@uw.edu
}

\author{
Susan Bolton \\ Professor, School of Environmental and Forest Sciences \\ Adjunct Professor, Civil and Environmental Engineering \\ Adjunct Professor, Department of Global Health \\ University of Washington \\ Seattle, WA 98105 \\ sbolton@uw.edu
}

\author{
Jorge Alarcon \\ Architect, IUCI On-site Coordinator \\ Fundacion San Marcos \\ Lima, Peru \\ contracoco@gmail.com
}

\begin{abstract}
The Informal Urban Communities Initiative is a design activism, service learning and research program based in Lomas de Zapallal, an informal urban settlement in northern Lima, Peru. The initiative focuses on the design, implementation, monitoring and evaluation of community-driven interventions in the built environment and, in response to priorities articulated by community members, places particular emphasis on the integrated, interdisciplinary design of public green space. It aims to effect positive and sustainable change in Lomas de Zapallal, to build the capacity of designers to work effectively with poor urban communities and to gather evidence that informs best practices in project design and implementation in these contexts. The paper presents a descriptive overview of three Informal Urban Communities Initiative projects completed at the Pitágoras School; a primary school park, a secondary school stair and garden and a secondary school classroom. Reflecting upon the positive and negative lessons these projects provide when considered in tandem, the paper argues that community driven processes, multi-scalar interventions, interdisciplinary collaboration and long term, indepth engagement are essential components of effective design practice and education in informal urban communities.
\end{abstract}

Index Terms - community-based design, informal urban settlements, interdisciplinary

collaboration, service learning

\section{INTRODUCTION}

Accelerating urbanization and profound social inequity are closely related, defining issues of our era. In the next 30 years, virtually all of the world's population growth will take place in developing cities. By the year 2050, a third of the world's population (3 billion people) could live in informal urban settlements, or slums. Slums are born out of the complex interactions of social, cultural, political, environmental, economic and infrastructural systems and the challenges that 'slum' dwellers face are complex and multifaceted. They range from a lack of adequate sanitation to increased vulnerability to natural disaster. 
As synthetic problem solvers whose work addresses social, environmental, and technical issues in the built and natural environments, designers, including landscape architects, architects and engineers, have much potential to lead efforts to confront these challenges. And yet, design practice and education remain largely confined to affluent cities. Without adequate training or experience, designers remain ill-equipped to deal with the unique challenges of poor urban contexts and susceptible to mistakes typical of many development projects (implemented by NGOs, volunteer tourists, and charities alike). Short term engagements, superficial understandings of context and the conceptualization of community members as 'victims', undermine local project ownership, limit long term project sustainability and forfeit opportunities to learn from experience., ii, iii, iv In many cases, service learning programs compound this problem. They often focus primarily on student learning experience with little consideration for community impacts and perpetuate externally driven approaches to community development. ${ }^{\mathrm{v}, \mathrm{vi}, \mathrm{vii}}$

A growing body of service learning discourse calls for increased sensitivity to community perspectives in the structuring and evaluation of service learning programs. ${ }^{\text {viii, ix, } x}$ Building upon this foundation and responding to the challenges of slum development, a team consisting of faculty and students in the University of Washington's (UW) Department of Landscape Architecture, School of Environmental and Forest Sciences and UW Department of Global Health, collaborators from the Universidad Nacional Mayor of San Marcos and design professionals from Engineers without Borders and Architects without Borders-Seattle have worked since 2010 to establish the Informal Urban Communities Initiative (IUCI). The IUCI is a design activism, service learning and research program based in Lomas de Zapallal (LdZ), an informal urban settlement (slum) in northern Lima, Peru. It focuses on the design, implementation, monitoring and evaluation of community-driven interventions in the built environment and, in response to priorities articulated by community members, places particular emphasis on the integrated, interdisciplinary design of public green space. The IUCI team funds and helps manage small projects in partnership with community members that are intended to catalyze ongoing community-driven development. The goal is to effect positive and sustainable change in LdZ, to build the capacity of designers to work effectively with poor urban communities and to gather evidence that informs best practices in project design and implementation in these contexts.

The IUCI espouses a practical, experiential, hands-on and fluid approach to design education. It posits that in order to learn how to work effectively in informal urban communities, students must:

- actively engage in practice

- monitor and evaluate the impacts of interventions

- critically reflect upon and react to these impacts

The integration of design education, practice and research is critical.

With this in mind, the following paper focuses on practice within the IUCI. It presents a descriptive overview of three IUCI projects as background and then reflects upon the positive and negative lessons these projects provide when considered in tandem. Based upon their influence on the implementation and relative success of IUCI projects, the paper argues that community driven processes, multi-scalar interventions, interdisciplinary collaboration and long 
term, in-depth engagement are essential components of effective design practice and education in informal urban communities.

\section{OVERVIEW OF THE INFORMAL URBAN COMMUNITIES INITIATIVE}

In Lima, Peru more than 3 million people live in slums. They lack access to water, sanitation, adequate housing and public green space. Within a relatively short period of time, low elevation Andean glaciers that supply much of the city's water will melt as a result of climate change and already insufficient water networks will run dry. ${ }^{x i}$ Changing temperatures and precipitation in Peru's agricultural regions will decrease agricultural productivity, increase urban food insecurity, undermine rural livelihoods and contribute to increasing urbanization. By 2050 Lima's population is expected to increase to 16 million. ${ }^{\text {xii }}$ Rapid informal urban growth will exacerbate water shortages, further degrade the region's few remaining ecologically intact landscapes and reduce access to public green space. Green space provides multiple benefits to human wellbeing and the environment. ${ }^{\text {xii, }}$ xiv, $x v$ At less than 2 square meters per capita, Lima has far less green space than most cities. ${ }^{\text {xvi }}$

The IUCI consists of two primary activities; 1) Seattle-based Design Activism studios and seminars and 2) on-site programs in LdZ (Figure 1). During Design Activism studios, students from multiple disciplines gain abstract knowledge of the contextual conditions of LdZ and explore creative, integrated approaches to urban infrastructure and multifunctional public spaces and hold Skype conversations with the community. During on-site programs, they are exposed to the community they imagined in Seattle, often with dramatic changes in perspective, and work together with faculty, professionals and community members to conduct participatory design workshops, execute design interventions and evaluate the impacts of these interventions. Upon returning to Seattle, they have the opportunity to participate in IUCI seminars, digest and reflect upon their experiences and share their first-hand knowledge of site and community with students who have yet to visit Peru. Their experiences and knowledge, inform subsequent Design Activism Studios and on-site projects. After graduation, some students continue to participate in the IUCI as members of Architects w/o Borders-Seattle.

This cycle repeats itself and aggregates as faculty and students return to the same location. Over time, it aims to increase the number of designers with experience working in informal urban communities, project by project and to help LdZ community members and other slum communities worldwide achieve their immediate and long term goals. 


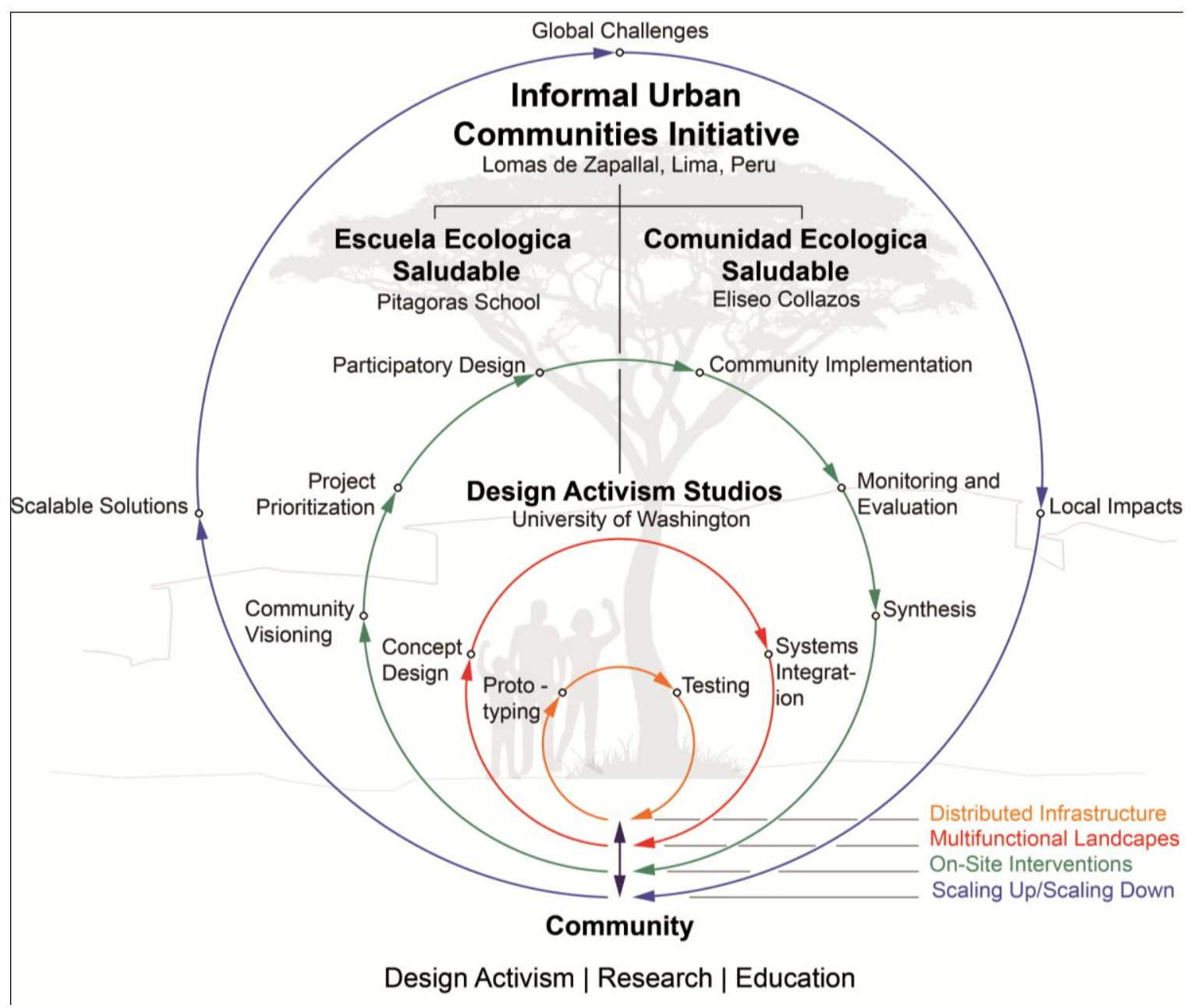

FIGURE 1

DIAGRAM ILLUSTRATING THE ORGANIZATION AND DYNAMICS OF THE INFORMAL URBAN COMMUNITIES INITIATIVE. TO READ, START WITH "COMMUNITY" AT THE BOTTOM AND MOVE UP ALONG THE VERTICAL ARROW. TAKE A LEFT HAND TURN AT ANY OF THE CIRCLES AND FOLLOW THE ARROWS AROUND. UPON RETURNING TO THE VERTICAL ARROW AT THE BOTTOM CONTINUE AROUND THE SAME CIRCLE AGAIN OR SHIFT UP OR DOWN TO ANY OTHER CIRCLE. SPIRAL IN, SPIRAL OUT, OR BOTH. EACH OF THE CIRCLES REPRESENTS A DIFFERENT SCALE AND/OR PROCESS WITHIN THE IUCI AND MOVEMENT AROUND AND BETWEEN THEM REPRESENTS THE WAYS IN WHICH THEY INFORM ONE ANOTHER.

\section{IUCI ON-SITE PROGRAMS}

IUCI projects are organized around two programs based at two sites in LdZ: 1) Escuela Ecologica Saludable (EES) projects are based at the Pitagoras School, and 2) Communidad Ecologica Saludable (CES) projects are based in the neighborhood of Eliseo Collazos. EES projects have a longer history than CES projects and there has been more opportunity to assess 
their impacts. Accordingly, the paper focuses primarily on the implications of EES projects; a primary school park, a secondary school stair and a secondary school classroom.

\section{Escuela Ecológica Saludable (EES) Projects}

The EES program began during a series of participatory planning workshops conducted at the Pitágoras School in July and August of 2010. Parents, teachers and students brainstormed ideas to improve the school, drew the campus and identified the school's existing resources, challenges and opportunities for development. After presenting their ideas, they ranked and voted on project priorities which included new secondary school classrooms and public green spaces for gathering and recreation. These workshops formed the basis for subsequent EES projects.

\section{Primary School Park and Cooking Classes}

During August and September of 2011, six UW students from multiple disciplines travelled to LdZ to participate in a 4 week UW International Exploration Seminar. During their time on site, they helped design and construct a park at the Pitágoras primary school and taught primary school students about nutrition during a series of cooking classes, activities indicated as high priority by the parents, teachers and students. The project began with a discouraging initial meeting with very low attendance, due to the unreliability of one of our primary contacts at the school. However, after reaching out to new community leaders the project quickly gained momentum. Four community workshops with much higher attendance built upon the workshops conducted at the school in 2010 and helped define the project. During the first two meetings, participants elected to pursue the design and construction of a park on a barren, sandy slope located between the primary school classrooms at the south end of campus and the school's central gathering area. At the third community meeting, parents and primary school students drew their ideas for the park's design. UW students synthesized ideas from the parents' and students' drawings and produced three preliminary park designs. They presented the designs at a fourth meeting. Meeting participants selected their favorite design and identified elements from all three designs that appealed to them.

The final park design represented a synthesis of participant preferences and feedback. It included an outdoor classroom, shaded areas for gathering and recreation and a learning landscape with hundreds of local, ornamental and productive plants. 'Piedra de laja' paths, constructed with locally available stone, local skills and local labor, connected the primary school to the school's central courtyard. Water conserving drip irrigation and sawdust-filled planting pits and a subsurface clay pot irrigation system that supplied recycled water from the schools hand-wash station directly to plant roots, addressed the increasingly pressing issue of water scarcity in Lima (Figure 2). 


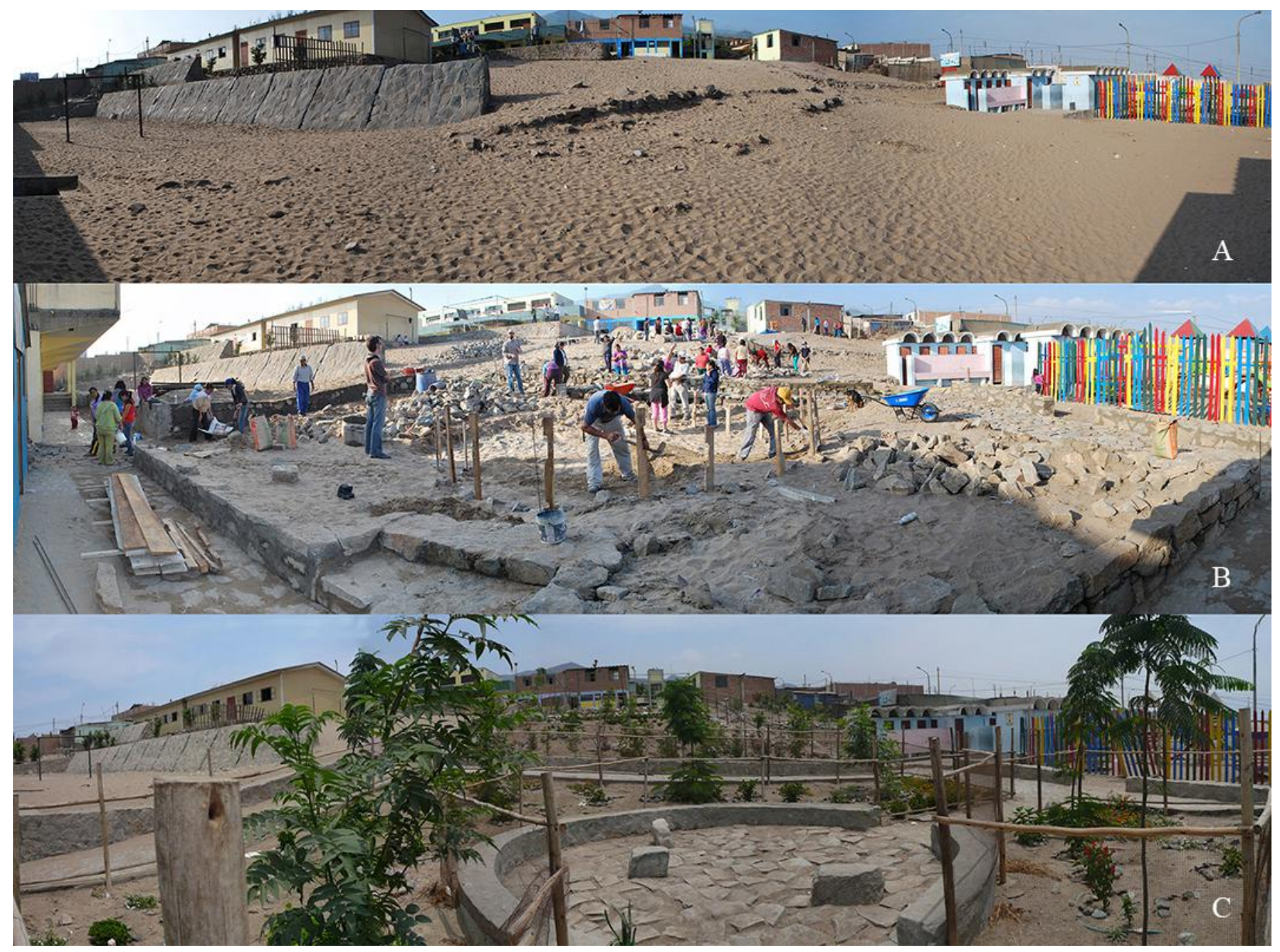

FIGURE 2

PRIMARY SCHOOL PARK - A) EXISTING CONDITIONS B) CONSTRUCTION C) COMPLETE

During the construction process, more than 300 primary school parents worked with students and a small team of local craftspeople through a 'faena' or volunteer labor system organized by the Pitágoras parents association. Workshops led by local experts were offered to the parents working on the project to teach them about green space both at the school and at their homes. They learned about proper planting techniques, watering and maintenance, worm composting and how to grow their own vegetable gardens. Participants also learned new construction skills while working on the job. At least one women gained employment as a stone mason as a result. Community members continued to work on the project after students returned to the US. It was completed in just over 2 weeks for less than $\$ 5000$ in material and paid labor costs.

During cooking classes, children learned to bake cookies and banana bread, English words for ingredients and the importance of good hygiene and nutrition. Following each class, they sold their baked goods to parents, craftspeople and UW faculty and students, perhaps laying the seeds for future careers culinary entrepreneurs.

During a subsequent International Exploration Seminar in 2012, one year following the primary school park's construction, UW students and faculty conducted an assessment of its evolution and impacts. Despite a teacher's strike that coincided with their visit, they were able to arrange Participatory Impact Assessment (PIA) workshops with teachers and students. They also 
documented the conditions of the park's constructed elements and inventoried the growth and survival of the park's flora and fauna.

The results of the assessment indicated that students and teachers viewed the park as an important ecological learning environment, place of gathering, access route and beautiful setting that improved mental wellbeing. The majority of the vegetation planted in 2011 survived and flourished, demonstrating ongoing maintenance and community ownership. Fauna including birds, snails and butterflies and other insects had proliferated in the habitat the park provided. The park's stone paths and other hardscape elements survived the year without damage.

At the same time, the park had not survived the year unscathed. A galvanized mesh fence protecting the planted areas had deteriorated in the thick fog that blankets the community for much of the year and the park's recycled water irrigation system had ceased to function properly both because primary school students broke several clay irrigation pots and because someone disposed of paint in the hand-wash station which gummed up the sand filter. UW students worked with community members to construct a new wooden fence, to clean and re-commission the recycled water system and expand the school's drip irrigation system using plastic drip tubing and drippers.

In 2013 the IUCI team repeated their physical assessment of the park. It revealed strengths and weakness similar to the 2012 assessment. The 'piedra de laja' paths remained undamaged and, although there were signs of nitrogen deprivation in a few plants and other plants were in need of pruning, the majority of the vegetation continued to flourish. The parents had painted the new fence blue and it remained in good condition. Unfortunately, the sand filter had been contaminated again and all but a few of the clay pots had been broken. Fortunately, the drip irrigation system and sawdust planting pits were functioning well and the park remained well irrigated. The sand filter has been disconnected since the school cannot control what goes down the hand washing drain.

\section{Secondary School Stair}

At the same time UW students and faculty were conducting the 2012 primary school park assessment, they also facilitated a series of participatory design workshops similar to those conducted in 2011. During the first workshop, participants elected to pursue a project in the secondary school that, like the primary school park, provided access from the school's central campus to its peripheral classrooms. The scope of the project that the parents initially proposed was too large to tackle within the limited time frame and budget of the Exploration Seminar. In response, the IUCI team proposed dividing the overall project into three sections and developed initial schemes for each. The sections included 1) a stairway that leads from the central campus up to the secondary school, 2) a path providing circulation between the secondary school classrooms and 3) a plaza at the secondary school's uppermost classrooms. In the next workshop, parents chose to pursue the stairway and provided additional design input that informed a final round of design synthesis.

The final design transformed a garbage dump that occupied the site into a series of terraces, a stairway and a broad entry landing leading into the secondary school. It served as an extension of the primary school park and provided additional access across the school's campus (Figure 3). 


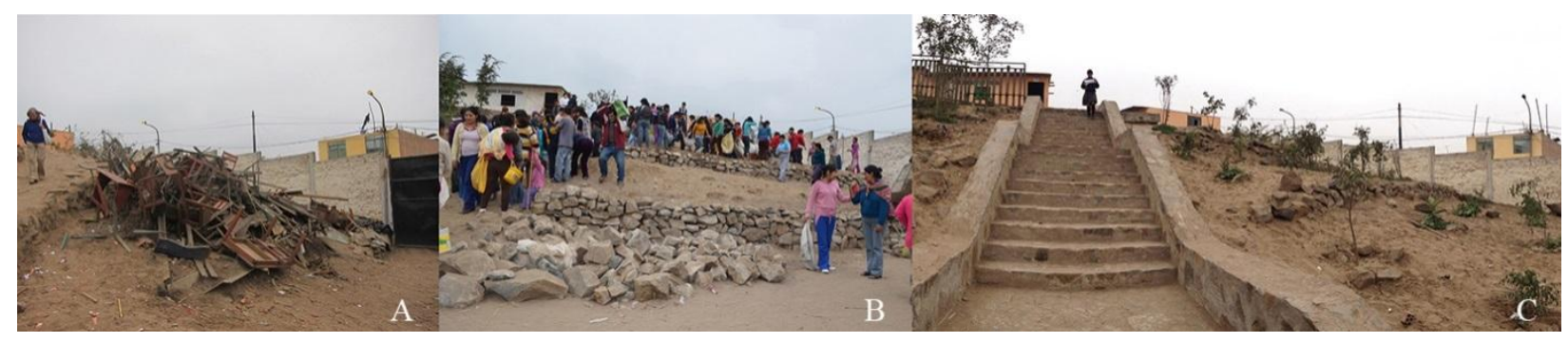

FIGURE 3

SECONDARY SCHOOL STAIR - A) EXISTING CONDITIONS B) CONSTRUCTION C) COMPLETE

More than 500 parents participated in the construction process. They cleared the garbage dump site, moved enormous amounts of sand and stone and worked with students and craftsmen to construct retaining walls, the stair and the plaza. Planting was beyond the scope of the Exploration Seminar budget. However, parents purchased and planted many trees in the months following the departure of the IUCI team.

In 2013, UW faculty and students returned to the school to assess the conditions of the secondary school stair. The stair itself remained in very good condition and had become the primary means of circulation between the central campus and the secondary school. Pitagoras students and parents had planted trees on the terraces and constructed a provisional fence to protect them. They had also expanded the project to include the secondary school path and upper plaza they had envisioned during participatory planning workshops the year before. The school's circulation network now reaches across the entire campus.

At the same time, the project expansion came at a cost. In order to build the extended path and upper plaza, parents made use of bricks intended for the construction of the secondary school classroom project (described below). They also partially deconstructed and repurposed the materials from some of the dry laid stone retaining walls supporting the terraced garden adjacent to the stair. As a result, the garden's sandy slope began to erode. The parents and the school director explained that they had plans to reconstruct these and other retaining walls later in the year when resources become available. When the IUCI team visited the site in March of 2014 they found that, indeed, the parents had undertaken these repairs.

\section{Secondary School Classroom}

Many of the existing classrooms at the Pitágoras School are overcrowded and constructed from non-durable materials. They have poor lighting and poor ventilation and are subject to temperature extremes during the summer $\left(>40^{\circ} \mathrm{C}\right)$ and winter $\left(<15^{\circ} \mathrm{C}\right)$. They are ill-suited to productive learning and have the potential to contribute to the spread of endemic diseases such as tuberculosis. In response to these conditions and based upon the priorities expressed during the 2010 community planning workshops at the Pitágoras School, the IUCI team initiated the design of a 'Healthy and Ecological' classroom building (Figure 4). 


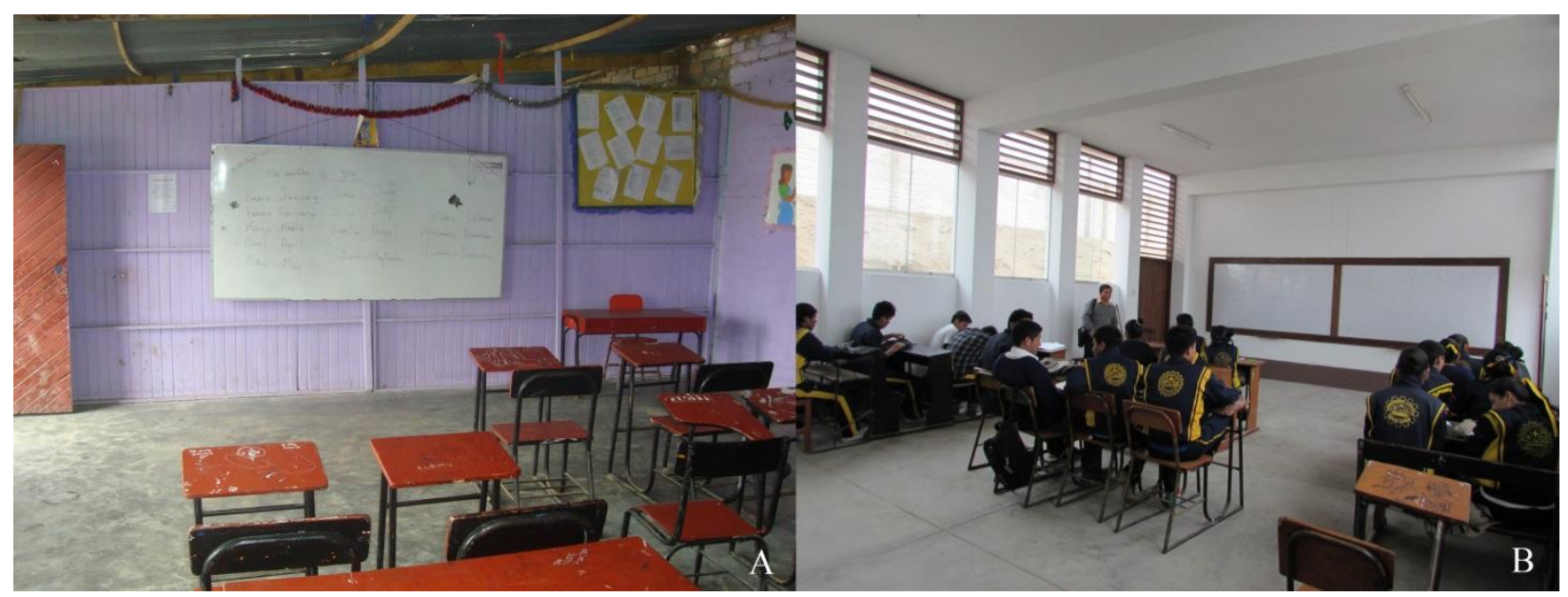

\section{FIGURE 4 \\ SECONDARY SCHOOl ClASSROOM - A) EXISTING CLASSROOMS B) NEW CLASSROOM}

Unlike the primary school park and the secondary school stair, the classroom was subject to the regulations of several institutional stakeholders and building codes. These regulations provided a framework for the distribution of project funds, stipulated that the project had to go through an official permitting process and required that a licensed contractor construct the project. Accordingly, although parents and UW students were involved in the design process, they were barred from direct participation in the classroom's implementation.

Based on initial estimates and an available budget of $\$ 20,000$, plans were made to construct 2 of the 10 classrooms in the classroom building. The design team completed construction documents and filed permit applications with the municipality in March 2011. The permitting process was subsequently delayed for several months due to the repeated suspension of the mayor for corruption. When permits for the project were finally approved, the project's contractor withdrew from the project the day before construction was scheduled to commence citing the extensive permitting delays and a newly acquired surplus of high profit work in Lima's affluent central districts. After three months of searching, the team found another licensed contractor willing to work in LdZ. However, upon revisiting the construction budget, the new contractor estimated project costs at more than $4 \mathrm{X}$ the original estimate and well beyond typical construction costs in Lima. The steep rise in costs was attributed to the loss of donated materials from the original contractor, Lima's booming construction industry, rising materials costs and the hardship associated with completing a project in a slum community. In response, the design team worked to redesign the classrooms to reduce costs and raised funds to supplement project budget.

Construction commenced in September of 2012 and proceeded in fits and starts. Two setbacks occurred during this period. The first involved the robbery of close to $\$ 2000$ of the contractor's construction equipment. This occurred even though the tools were in a locked storeroom in the school's walled and locked compound with a live-in security guard. The second came about when, as mentioned previously, the Pitágoras parent's group utilized bricks intended for construction of the classroom roof to build paths in the secondary school. The procurement of additional funds was necessary to make up for these losses.

The primary classroom structure was completed in March of 2013 and secondary students began taking classes in the classroom in March of 2013. Final construction tasks including the 
installation of doors, windows, an impermeable roof (with newly purchased bricks), final painting and the installation of a whiteboard were completed in October, 2013. The project was officially inaugurated on November $13^{\text {th }}, 2013$ - three years and four months after it began.

Although a formal assessment of the classroom's impacts is yet to be completed, it is likely to provide a number of benefits to the school. Its design includes ample space for students and high ceilings. It takes advantage of natural wind currents and day-lighting to create a low energy, comfortable and healthy learning atmosphere. It is seismically engineered and constructed from durable materials including concrete and clay block. Initial feedback from the school director and the Pitágoras parent's association indicates that, despite the long road to completion, the classroom is a welcome change at the school and represents an enormous improvement over the school's other teaching facilities. With its high ceilings, the director calls it a 'cathedral' of learning.

\section{DISCUSSION}

The EES projects provide a number of lessons relevant to the future evolution of IUCI as well as design practice and service learning in informal urban communities in general.

\section{Working at Schools}

Working with schools has both negative and positive attributes. Improving the setting for education has long term potential to increase a country's workforce and civil society. At least in Lima, there is a large volunteer workforce available for manual labor in the form of various parent organizations. This keeps overall costs down and facilitates local ownership and involvement. On the other hand, large schools often have little oversight of students and students are not always particularly responsible. As a result, issues such as contamination of the sand filter and the damage to the clay pot irrigation system are difficult to control. It is important to recognize potential pitfalls of having hundreds or thousands of unsupervised youth interacting with your projects and take measures to safeguard against them. Build with cost effective durable materials, integrate capacity building programs for teachers, students, and staff into all projects, work with project participants to establish protocols for project maintenance and design redundant systems so that if one component fails the entire system will continue to function.

\section{Value Local Knowledge, Resources and Priorities}

Whereas many service learning and development projects are conceived and constructed primarily by foreign students, faculty, professionals and/or other volunteers, the EES projects attempted to leverage local knowledge and resources. The intent was to foster self-reliance by placing responsibility for project planning and execution on community members themselves and strengthen project sustainability by engendering a sense of local ownership and commitment.

Of the three projects, the Primary School Park took advantage of local knowledge and resources to the greatest extent. Parents, students and teachers, prioritized, designed and constructed these projects themselves with the assistance of UW faculty and students and small teams of skilled craftspeople. It made use of local building materials and leveraged the skillsets of community members. Despite complications related to the fence and clay pot irrigation 
system, the park has been well maintained. Parents have purchased paint and cement for repairs and planted additional plants.

The Secondary School Stair project also took advantage of local knowledge and resources, but its location on an unstable slope required slightly more professional involvement and skilled labor. Despite the removal of stone from its retaining walls, the stair project has grown both in terms of its plantings and scale. Parents used the stone and the confiscated brick to complete the pathways to the upper classrooms as shown in the original design. They also invested their funds in additional trees. These developments serve as clear signs of the community investment and reflect positively upon the IUCI's potential to catalyze community driven efforts.

In contrast, although the Secondary School Classroom was a community priority and parents provided input on its design, by necessity it evolved into a professionally driven project. A strict regulatory environment, political corruption, a poorly managed permitting process and commercial interests in a growing economy converged to nearly bring the project to a halt. Lack of direct community participation in project construction undermined local ownership and may have contributed to the theft of tools and the misunderstandings about the use of the bricks intended as roof materials.

This comparison brings the importance of community driven processes into sharp focus and suggests that regulations governing the built environment in informal urban communities, though intended to promote health and safety and improve quality of life, can sometimes have the opposite effect. As additional classrooms and other projects subject to regulation become the focus of the IUCI, there is a strong temptation to pursue them 'informally' through unofficial channels. Such an approach would likely reduce project costs and timelines, increase the likelihood that the projects would actually get done and assure that community members remain engaged in, take ownership of and benefit from projects throughout their lifecycles.

Ultimately however, the risks of such an approach could outweigh its benefits. For instance, the IUCI's institutional partners are compelled to comply with legal processes (despite the inherent prejudice of these processes) and would be unlikely to support a more subversive approach to project implementation. It might damage the IUCI's relationship with local governing bodies and prompt these bodies to take an obstructionist, rather than a supportive stance towards future IUCI projects (at least while they remain in office). Over the long run, it could also undermine the agency of local government by effectively excusing them from their responsibility to act on behalf of their constituents.

A more restrained and perhaps more advisable approach to future regulated projects would involve;

1) taking steps to overcome the pitfalls experienced during the classroom project including a) building substantial contingencies into project budgets and schedules to account for unforeseen delays and escalating construction costs b) establishing an open and transparent dialogue with community members so they are fully aware of the steps involved in the permitting and construction processes and have realistic expectations of how the project will unfold c) working as closely as possible with municipal authorities to fast track permitting processes and d) requesting that licensed contractors engaged in project construction take advantage of volunteer labor and/or employ locals, and

2) advocating for the integration of community-driven process into the regulatory frameworks that govern the built environment in informal urban communities. Revisions to existing regulations might include a) streamlining permitting processes and placing permitting authority in the hands of entities outside the political realm (so projects can proceed even when 
the mayor is suspended) b) providing incentives that encourage professionals to prioritize and focus as much energy on social projects as they do on for-profit projects, c) reducing contractor licensure requirements so local contractors and craftspeople can oversee projects with more limited professional assistance and d) fostering increased community participation in officially recognized project implementation.

As the IUCI continues to evolve, the IUCI team will continue to work in collaboration with community members to pursue small projects that fall outside the jurisdiction of strict regulation so as to build an evidence base that further substantiates the effectiveness of community driven processes. At the same time, and particularly when community priorities call for it, the team will undertake regulated projects and work in close collaboration with stakeholders at multiple scales to streamline the processes of project implementation. Students and community members benefit from both of these processes. Experience with participatory design methodologies and the navigation of regulatory systems not only strengthens their ability to execute projects, it also equips them to act as advocates for change at the scale of policy and governance.

\section{Pursue Multi-scalar Interventions}

In the early 2000s the Peruvian Ministry of Education completed a masterplan for the Pitágoras School. The plan took a large scale, high cost, boiler plate approach to school design with limited community input. More than 10 years later, nothing has been done to move this project forward. Echoing the difficulties experienced during the implementation of the EES secondary school classroom, the project fell victim to its association with particular political regime, election turnovers and a lack of continuity in political agendas.

In contrast, the EES projects adopted an approach to community development that integrated small scale intervention and adaptable long term planning. They demonstrate that multi-scalar approaches to design intervention offer a viable alternative to the traditional 'masterplan'. The visioning workshops held at the Pitágoras School provided a cohesive armature for the community-driven pursuit of the smaller scale classroom, park and stair projects. Each year, parents revisited their vision for the school and each project undertaken as part of the EES represented a step towards its fruition. The integration of larger scale, longer term goals with more immediate and achievable interventions have proven critical to the EES program's, albeit modest, progression.

The same can be said of the EES projects themselves. The classroom project constituted a small part of a larger building. The primary school park as originally implemented represented perhaps $60-70 \%$ of the complete project design. The secondary school stair was conceived as a portion of a more extensive circulation system. In the cases of the park and stair, community members took it upon themselves to continue with construction and invest in maintenance. Larger scale designs provided a contingent roadmap for project expansion and initial interventions served as the impetus for further action. In the case of the classroom, had the IUCI team taken an all or nothing approach to the construction of the entire building, it is likely they would still be waiting to lay the first stone. The hope is that, now that the pilot classroom is complete, it will serve as a proof of concept, help attract additional government or donor support and lead to the completion of additional classrooms - perhaps one classroom at a time.

In environments where resources are scarce and politics are volatile, thinking big and trying to act big can mean that nothing gets done. Thinking big and acting incrementally provides a platform for contingent planning. It allows communities and their partners to ease their way into 
development projects and increases the likelihood that, step by step, projects will move slowly forward. As the IUCI continues to evolve the IUCI team will continue to pursue a multi-scalar approach to design, introducing students and community members to both long term visioning and tactical design and implementation.

\section{Foster Interdisciplinary Collaboration}

Interdisciplinary collaboration strengthened the project teams' ability to respond to diverse community expressed priorities ranging from the design and construction of buildings and parks to teaching school children about nutrition. It allowed them to engage in both participatory/qualitative (e.g. Participatory Impact Assessment exercises to assess the park) and quantitative (e.g. plant growth and survival studies) evaluations of project evolution. Design students gained novel insights into human health and environmental considerations while students from environmental and health related disciplines gained insights into creative design processes. Community members learned from students, faculty and craftspeople, while, at the same time, sharing their own expertise. Undergraduate students learned from graduates, junior faculty from senior, professionals from academics and vice versa.

At the same time, interdisciplinary collaboration contributed to the overextension of the project team on many occasions. During the 2012 Exploration Seminar, for example, ecological assessment and fence repair at the primary school park, participatory design of the secondary school stair and a pilot fog collection project in EC were underway concurrently. The quality and depth of each of these projects likely suffered as a result of their breadth. On other occasions, disciplinary differences in perspective spurred debate. Scientists and architects on the project team, for example, did not always agree on the relative importance of aesthetics, function and cost.

The IUCI team was able to bring most disagreements, along disciplinary lines or otherwise, to amicable resolution. However in a small number of cases, especially when time was short and team members were tired, certain decisions become unnecessarily contentious. The reasons for this contention were complex and varied but, at a basic level, they resulted from a lack of a shared understanding of roles, responsibilities and decision making processes. This is a critical component of collaborative work that is easily overlooked in the early stages of team building when projects have yet to encounter significant road bumps.

The lessons are similar to those related to multi-scalar intervention; think broadly, holistically and across disciplines, and focus interdisciplinary efforts on achievable projects and goals. Embrace debate as an opportunity to learn and prepare for disagreement and miscommunication by defining expectations, roles, responsibilities and decision-making processes. Pursue collaborative dialogue whenever possible but make it clear from the start that final decisions must ultimately fall on the shoulders of those responsible for project mission and outcomes.

\section{Establish Long Term Relationships}

In 2011, just before the primary school park project began, an NGO constructed a playground at the Pitágoras primary school. By 2012 (within several months of its opening), the playground had deteriorated to the point at which it was too dangerous for children to play on and it was closed. By 2013, all of the playground equipment had been removed and disposed of. As far as 
the IUCI team is aware, the NGO never returned to the school to evaluate the sustainability or impacts of their efforts. Parents and teachers at the school have come to view the NGO in a negative light. In fact, the school administrators express negative opinions about the NGO's country of origin as a whole. It is important to impress upon team members that, like it or not, they represent their university, their faculty leaders and country of origin.

The playground project exemplifies typical 'one off' development projects and/or service learning programs wherein groups enter a community with little or no knowledge of local circumstances, build a project and leave shortly after project completion, never to return. It highlights what is perhaps the most compelling and cross-cutting lesson of the EES projects; the importance of long term commitment. The IUCI team's ability to: 1) effectively understand and assimilate the knowledge, resources and priorities of Pitágoras School parents, students and teachers; 2) to design and implement the park, stair and classroom projects and 3) to assess and learn from these projects has depended upon multiple visits to LdZ over the course of several years. The classroom project would likely never have reached completion were it not for the long term dedication of the IUCI team.

It is important to note, that it is not just the longevity of this relationship that matters. It is also the quality of that relationship. The quality of the IUCI's relationship with LdZ community members is one of its strengths. Unlike many service learning programs, the IUCI team travels to $\mathrm{LdZ}$ for up to 3 months every year and employs a Lima-based project coordinator who visits the site intermittently throughout the year. Even though the students may vary from year to year, the same two faculty members continue to lead the effort. And yet it falls short of the ideal. Student and faculty engagement in projects is often constrained by academic calendars that do not coincide with local calendars. Given the short duration of UW International Exploration Seminars, projects such as the park and the stair have unfolded at rapid pace with little time for reflection. The initiative's 3 month and intermittent on-site presence remains limited and, as is indicated by actions such as the misappropriation of roofing materials, the team's ability to collaborate and communicate effectively with community members remains imperfect. As noted earlier, at times one needs to make changes to local contacts if they prove not to be reliable or responsible. Under ideal circumstances, the IUCI would not only foster a long term relationship with the community, it would also maintain a more permanent presence on-site. Students would engage in on-site project activities throughout the year and participate in the IUCI through multiple avenues including service learning seminars, independent studies, theses and capstone projects. The initiative's on-site coordinator would work in the community on a daily basis. Community members themselves would eventually become instructors. As the IUCI evolves the IUCI team continues to work towards these objectives.

\section{CONCLUSION}

Although the scope of informal urban development is immense, our response to it should be small, careful and contextual. The quality of our work matters. It is of paramount importance that we assess project outcomes, reflect upon our experiences and adapt our approaches in accordance with the lessons we learn. In doing so, we stand to strengthen the foundations of 'slum-based' practice and service learning, to encourage students and community members alike to engage in reflective design activism and to nurture the ongoing critical development, dissemination and expansion of effective practice in informal urban communities. 


\section{ACKNOWLEDGMENT}

The Informal Urban Communities Initiative is supported by the University of Washington Department Of Landscape Architecture, School of Environmental and Forest Sciences, Department of Global Health, School of Nursing and the UW Global Health and Environment Fellows. It also receives support from the Fundacion San Marcos, Architects w/o Borders Seattle, Engineers w/o Borders - Service Corps, the R Hunter Simpson Foundation, the Barbara Wyman Fund and the UW Royalty Research Fund. The authors would like to thank all of the students and community members who have participated in the IUCI over the past 5 years.

\section{REFERENCES}

i Alnoor Ebrahim, "Accountability in Practice: Mechanisms for NGOs," World Development 31, no. 5 (2003), 813-829.

ii Paul Farmer, Pathologies of Power, Health, Human Rights and the New War on the Poor (Berkeley, CA Los Angeles,Ca and London, UK: University of California Press, 2005), 153.

iii Daniel A. Guttentag, "The Possible Negative Impacts of Volunteer Tourism," International Journal of Tourism Research 11, no. 6 (2009), 537-551.

iv Jeremy Griffin, 'Local Residents' Responses to Tourism as a Framework to Understand Hosts' Responses to Short-Term Missions," Ashbury Theological Seminary 68, no. 2 (2013), 134159.

v John W. Ebey, "Why Service Learning is Bad," http://www.messiah.edu/external_programs/agape/servicelearning/ articles/wrongsvc.pdf (accessed December, 26, 2013).

${ }^{v i}$ Elizabeth Tryon et al., "The Challenge of Short Term Service Learning” Michigan Journal of Community Service Learning 14, no. 2 (2008), 16-26.

${ }^{v i i}$ Randy Stoecker and Elizabeth Tryon "Unheard Voices: Community Organizations and Service Learning," in The Unheard Voices: Community Organizations and Service Learning (Philadelphia, PA:

Temple University Press, 2009), 1-18.

viii Laurie Worrall, “Asking the Community: A Case Study of Community Partner Perspectives," Michigan Journal of Community Service Learning 14, no. 1 (2007), 5-17.

ix Jini Puma et al., "A Case Study of a Community-Based Participatory Evaluation Research (CBPER) Project: Reflections on Promising Practices and Shortcomings," Michigan Journal of Community Service Learning 15, no. 2 (2009), 34-47.

${ }^{x}$ Humphrey Tonkin, "A Research Agenda for International Service Learning," in International Service Learning: Conceptual Frameworks and Research (Sterling, VA: Stylus Publishing, 2011), 193.

${ }^{x i}$ James Painter, "Deglaciation in the Andean Region, UNDP Human Development Report 2007/2008, Fighting Climate Change: Human Solidarity in a Divided World," (New York, NY: UN Development Programme) 1-13. 
${ }^{\text {xii }}$ Cecilia Castro, Gunther Merzthal and Rene van Veenhuizen. "The potential for treated wastewater use in Lima," in SWITCH in the City, Putting Urban Water Management to the Test (The Hague,NE: IRC International Water and Sanitation Center, 2011) 68-83.

xiii Christopher A. De Sousa, "Unearthing the Benefits of Brownfield to Green Space Projects: An Examination of Project use and Quality of Life Impacts," Local Environment 11, no. 5 (2006), 577-600.

${ }^{\text {xiv }}$ Agnes E., van den Berg, Terry Hartig and Henk Staats. "Preference for Nature in Urbanized Societies: Stress, Restoration, and the Pursuit of Sustainability," Journal of Social Issues 63, no.1 (2007),79-96.

${ }^{x v}$ Jo Nurse, et al.. "An Ecological Approach to Promoting Population Mental Health and Wellbeing: A Response to the Challenge of Climate Change," Perspectives in Public Health 130 (2010), 27.

${ }^{x v i}$ Annie Murphy,"What's a walk in the Park Worth in Lima Peru?," Christian Science Monitor, December 24, 2013, http://www.csmonitor.com/World/Americas/2013/1224/What-s-a-walkin-the-park-worth-in-Peru(accessed December $27^{\text {th }}, 2013$ ) 